P\&A Año 3, N. ${ }^{\circ} 4$

enero-junio 2018

pp. [17]-31

\title{
Resumen
}

La enseñanza de la educación superior en general y la arquitectura en particular, así como la cultura arquitectónica, son necesarios y debemos comprender la incidencia de la teoría, la filosofía y la ciencia respecto a la enseñanza de la arquitectura. La calidad de un ambiente afecta e influye en la conducta de las personas. Hasta hoy, los modelos pedagógicos de la enseñanza se mantienen en la falsedad ingenua y en el prototipo de imágenes y visiones pasadistas, tardías y retrospectivas. Este ensayo académico está dedicado a dos grandes maestros como Juan Romero Almendras y Félix Mayorca Palomino, quienes fueron docentes de la Facultad de Arquitectura y Urbanismo, y supieron favorecer la identidad educativa por la teoría, la filosofía y la ciencia.

Palabras claves: Enseñanza, arquitectura, ciencia, teoría, filosofía.

\section{La incidencia de la teoría, la fillosofía y la ciencia en la enseñanza de la arquitectura*}

\author{
Homenaje póstumo a Juan Romero Almendras y Félix Mayorca Palomino \\ prestigiosos arquitectos, educadores y formadores de la conciencia urbano- \\ arquitectónico-medioambiental en la Facultad de Arquitectura y Urbanismo de la \\ Universidad Ricardo Palma.
}

\author{
Magíster Walter A. León Távara**
}

Recibido: 23 de agosto de 2017

Aceptado: 22 de enero de 2018

\begin{abstract}
Teaching higher education in general and specially architecture, and also architectonic culture, are necessary and we must understand the theory, philosophy and science incidence about teaching architecture. Environment quality affects and has influence on people behavior. Up to now, teaching pedagogical models have kept the naive falseness and in the prototype of pastist, late and retrospective images and visions. This academic essay is dedicated to two great masters such as Juan Romero Almendras and Félix Mayorca Palomino, who were professors in the Architecture and Urbanism Faculty, who knew how to be in favor of their educational identity by theory, philosophy and science.
\end{abstract}

Keywords: Teaching, architecture, science, theory, philosophy.

* La incidencia de la teoría, filosofía y ciencia respecto a la enseñanza de la arquitectura son complejos sistemas culturales de la vida contemporánea, el articulo proviene de la preocupación que el autor ofrece una metodología innovadora que sistematiza los principios cognoscitivos de la enseñanza en los diversos campos de la actividad científica, social y cultural en busca de una integración holística que implica una cuestión de derecho sobre la arquitectura y las enseñanzas de dos grandes docentes protagonistas de la conciencia urbano-arquitectónico-medioambiental.

** Magíster en arquitectura por la Universidad Nacional de Ingeniería. Arquitecto y docente de la Universidad Ricardo Palma. Estudios de docencia universitaria en la Universidad de Lima. Especialización en teoría, historia y diseño de la Arquitectura, con estudios de doctorado en estudios de medio ambiente y desarrollo sostenible por la Universidad Inca Garcilaso de la Vega. Miembro del Instituto cultural Perú Unu Chaska. Diseñador y productor de medios audiovisuales. 


\section{Introducción}

A lo largo del camino de la enseñanza de la arquitectura y próximos a celebrar el quincuagésimo aniversario de nuestra casa de estudios, los últimos alcances sobre la pedagogía universitaria han permitido ensayar nuevos y experimentales métodos de enseñanza-investigación-aprendizaje con relación a la arquitectura en el interior de la Facultad de Arquitectura y Urbanismo de la Universidad Ricardo Palma, como nuevas formas de abordar y proyectar el diseño arquitectónico, tratando de vincular los objetos físicoespaciales con sus contenidos y contenedores en las más diversas técnicas educativas de la arquitectura.

Es indudable, que la arquitectura en general y el diseño urbano-arquitectónico en particular se encuentran vinculadas a la epistemología del confort humano, que si no la entendemos menos la podemos enseñar, en ese sentido la arquitectura es la comunión de la ciencia, la tecnología y el arte, que como fenómeno cultural afecta los intereses del ser humano y el dominio espacial, reconociendo que el espacio incide y afecta la conducta humana.

Definitivamente el arquitecto se moviliza desde el tratado de la ciencia y entre las principales atribuciones de la epistemología con el estudio de los métodos y procedimientos entre los conceptos y las formas del espacio humano, en un sistema pendular en que los pensamientos (lógica, análisis conceptual, paradigmas), los sentimientos (fenómenos afectivos, creatividad, aspectos subjetivos) y las acciones (técnica, condiciones de habitabilidad, construcción, tecnología) sustentan la lógica arquitectónica; es decir el mundo de la teoría sustentada por los conceptos que en muchos casos no necesariamente corresponde a la realidad de un hecho arquitectónico, en tanto los aspectos tecnológicos por lo general corresponden a los criterios de la eficiencia.

La arquitectura, en su mínima expresión, es la autonomía de los conocimientos arquitectónicos; en ese sentido como pensamiento y lenguaje espacial, es esencialmente físico- geográfico y refleja el espíritu existencial de la sociedad de una determinada época como expresión de su medio.

La vigencia de la arquitectura se circunscribe a tres categorías denotativas: Ciencia, Arte y Tecnología; no se trata simplemente de un aparato conceptual de una estructura de conocimientos, sino una actividad de investigación que se desarrolla en una determinada sociedad porque además involucra a la historia, los hombres y el tiempo; por los aspectos conceptuales, empíricos, sociales, históricos y metodológicos.

No tendría mayor interés que encabezáramos este homenaje, centrado en torno a una lista de obras arquitectónicas, a un conjunto de conocimientos que no desembocan a instancias reflexivas superiores y caer en excesos y reacciones inútiles. La visión de comprender que la arquitectura tiene un origen independiente y puro como la música, es difícil de entender, más aún cuando sostenemos que la arquitectura es hacer arte, crear belleza con formas espaciales, puras, libres y abstractas, que en muchos casos no tengan nada que ver con las formas usuales de la naturaleza. No obstante, es oportuno y esencial reconocer que en el "principio de las cosas fue el ojo, luego la palabra", es esencial.

La arquitectura se organiza a partir de ideas, garabatos, principios, conceptos y paradigmas, que son imágenes generales abstraídas de las percepciones, es decir nuestra vida mental y pensamiento visual. Se inicia con las imágenes que se relacionan mutuamente con los conceptos que se refieren a las relaciones, operaciones y transformaciones como cualidades de las cosas que mantienen su identidad cultural a través del tiempo.

En muchos de los experimentos mentales que se han producido y que producen los arquitectos en la actualidad como situación imaginada ofrecen un espíritu emprendedor porque piensan en cómo crear valor y construir nuevos hábitats, en cómo mejorar una realidad, un sitio, un lugar, un paisaje cultural y/o una propuesta de valor que son absolutamente definitivas, y que han desempeñado un papel creativo de crítica importancia en 
la producción de los objetos arquitectónicos. Este enigma de semiótica espacial concebida como aparato conceptual es un modelo cognitivo de representaciones construidas a partir de los datos generados durante el proceso de investigación expresada como la inteligencia espacial, la elegancia formal y la composición contextual, es decir, se intenta valorar su capacidad de modificar la realidad a través de la propuesta de diseño urbano-arquitectónico.

La cultura arquitectónica es el conjunto de conocimientos integrados mediante creencias, valores, conductas y objetos arquitectónicos que la sociedad crea y transforma para mejorar el nivel de calidad de vida de una determinada población. Por ello, los arquitectos son científicos en un contexto histórico determinado, que trabajan con leyes y teorías en un proceso de trasposición conceptual y utilizan la ciencia para mejorar el mundo real. Es acumulativa porque construye nuevas miradas para explicar otras experiencias, se moviliza entre los informes de las observaciones y los principios de las teorías que son conceptos bastantes precisos con significados establecidos, que desencadenan su capacidad de valorar y generar los aparatos conceptuales con la realidad, convirtiendo el modelo de lo "que es" a lo que "debe ser", es decir el paso de un objeto fronterizo.

Es oportuno acotar el texto Espacio en el tiempo. La arquitectura moderna como fenómeno cultural (1945) ${ }^{1}$, en tanto, la estudiosa Emma Victorio Cánovas, dice:

Para Cartucho Miró Quesada la arquitectura moderna es ingeniería sublimada, un equilibrio entre ciencia y arte. El título del libro demuestra la influencia de Kant, y desde la Introducción se identifica plenamente con su teoría al afirmar que el tiempo y el espacio

1 El texto fue una obra esencial para comprender la historia de la arquitectura peruana. El libro se divide en dos partes, en la primera parte explica la correspondencia entre la arquitectura, la historia y la técnica, reflexiona sobre las ideas principales del movimiento moderno y reconoce que la arquitectura es un arte social; en la segunda, se refiere al aspecto formal y sostiene que la estética de la arquitectura moderna radica en la belleza abstracta de la idea pura, destaca su naturaleza científico-artística y propone que lo moderno debe ocupar el lugar de la tradición (Victorio, 2017). son dos elementos formales de la sensibilidad, las formas puras de la intuición sensible, los elementos a priori, en los que como formas o moldes van necesaria y totalmente encerradas las formas materiales que son las sensaciones... son las formas puras en las que se dan en nosotros las representaciones objetivas. (Victorio, 2017)

Asimismo, en el libro Introducción a la teoría del diseño arquitectónico del arquitecto Luis Miró Quesada, señaló de lo espacial a lo volumétrico, que:

Es evidente que la forma espacial-arquitectónica vista desde afuera, tiene necesariamente una consecuencia formal volumétrica $\mathrm{y}$, por lo tanto, la arquitectura no deja nunca de ser el "juego magnífico de volúmenes ensamblados bajo la luz". Por lo tanto, en el proceso creativo arquitectónico deben irse conjugando continuamente las exigencias de la forma espacial y de la forma volumétrica. (Miró Quesada, 1945, p.20)

La arquitectura a través de sus edificaciones; sea individual o colectiva, pública o privada; en tanto urbanismo -mediante sus edificios, calles, parques y plazas organizados y distribuidos en el espacio urbano-arquitectónicomedioambiental- contribuye a conformar el entorno creado para una propuesta de valor, donde se desarrolla y desenvuelve diariamente la existencia humana. Aquí se llevan a cabo las complejas relaciones que se establecen entre las personas, las formas, el estilo y el sentido de la vida social, el nivel de calidad de vida de la población, determinan la realidad de su cultura ambiental.

Entre la teoría del conocimiento y el conocimiento del espacio humano existe el valor de la relación entre la Arquitectura y los objetos arquitectónicos, por lo tanto, podemos decir que la relación que existe entre la ciencia y su objeto. La Gnoseología o teoría del conocimiento tiene como problema central aclarar la naturaleza del conocimiento arquitectónico. En la antigüedad, el mayor aporte de la Grecia Clásica fue el pensamiento humano en su modo sistemático, analítico y crítico, que a lo largo de su historia hasta nuestros años, la filosofía reconocía como amor a la sabiduría, ha intentado elaborar un discurso basado en 
fundamentos, principios y la socialización de los conocimientos.

\section{A. La historia, la investigación científica y la teoría de la arquitectura}

La historia se caracteriza por las acciones humanas usuales, y es el tiempo que aparece como el principio continuo, está formada en base a cambios precisamente de las continuidades de las nomenclaturas denominadas edades como también períodos de la historia por su forma de pensar y valorar la memoria histórica. Después de todo, se piensa la historia como la historia de la humanidad, la relación de la materia con los seres humanos en el tiempo y sus experiencias, teniendo en cuenta que el fenómeno de la naturaleza se vincula a la realidad mediante el sentido común.

La ciencia contemporánea tiende al reduccionismo de los principios fundamentales según la perspectiva de la física. En cuanto a la primera interpretación respecto a la tradición religiosa espiritualista, de trascendencia divina y el racionalismo occidental que proviene de Platón y, la segunda interpretación acerca del materialismo a ultranza, el único fenómeno de explicación que cuenta con la explicación material, descripción de lo físico, en tanto como lo definen los científicos; en pocas palabras se ha puesto en tela de juicio la coherencia de la humanidad y su evolución lógica de la humanidad.

El problema básico de nuestro tiempo como lo expresa Erich Kahler², en su texto Historia universal del hombre, dice que:

La humanidad como comunidad intrínseca había de tener un destino común, y si hay una cualidad humana y específica, ha de haber tenido una evolución. Si no hay un todo continuo, de la humanidad o de la naturaleza humana, no existe nada que pueda llamarse historia humana, igual que

2 El destacado Erich Kahler nacido en Praga 1885 y murió en Princenton en 1970, fue un filósofo y literato, estudió en las universidades de Berlín, Múnich y Heidelberg, y obtuvo un doctorado en la Universidad de Viena en 1911. no podría haber una biografía sin identidad continua de la personalidad. La historia supone algo más que el mero tiempo; la historia sólo tiene sentido si se puede considerar como una evolución humana única y lógica. De no ser así, sólo sería una masa incoherente de potencias que suben y caen, de individuos que crecen y mueren. La eternidad no tiene historia, como tampoco la tiene el caos. (Kahler, 2013, p.14)

Platón identificó el saber formalista e idealista con una postura abstracta y matematizable que se asentó en las bases del enfoque cuantitativo, método aceptable en el amplio desarrollo y aceptación en el mundo de la ciencia. Por el contrario la concepción de Aristóteles, por su aproximación al enfoque cualitativo, es sensible y buscó un trato directo con los objetos de la naturaleza, aquí se encuentra el diseño, por una metodología concreta, empírica, directa, analógica y sensible.

Entre los siglos XII y XIV, la sociedad del conocimiento de la época se caracterizó por conciliar las doctrinas cristianas para dar inicio a una serie de cambios que van a surgir con la ciencia moderna durante el Renacimiento, que en modo alguno fue heredara de la antigüedad clásica. No obstante, surgió la filosofía de la sociedad feudal en una época en que la religión era la ideología dominante. Esta época se caracterizó por la estrechez religiosa, el odio indisimulado por la ciencia, la justificación del yugo feudal, con sus afectos y defectos hipócritas al ascetismo como rasgos esenciales.

En el siglo XVII los descubrimientos más importantes fueron en la física, la ley de la gravitación de Newton, en las matemáticas, el cálculo infinitesimal de Leibniz; no obstante, el propio Newton proyectó, modeló e influyó en los numerosos pensadores y científicos de futuro con una ley sencilla y absoluta que permite entender el orden en el que Dios ha puesto al mundo. Sin embargo, el siglo XVIII con el desarrollo de la ciencia, la economía, las ideas sociales y políticas, fueron los antecedentes más claros de una revolución interesada sobre la naturaleza de la materia, las exploraciones sobre las profundidades del 
espacio y los fenómenos de las revoluciones científicas.

En 1789, estalló la Revolución Francesa, que fue un hecho histórico clave en el futuro de los acontecimientos en el mundo, y que hubo tres grandes cambios significativos como la Revolución Demográfica, la Revolución Agrícola y la Revolución Industrial.

El siglo XIX, podría ser definido como el siglo de las transformaciones, fue una época en la que surgió la reacción del espíritu humano contra todo lo que significó tradición, además aparecen nuevas ideas acerca del gobierno, la religión, la sociedad, la economía y la arquitectura.

La modernidad nació en Europa en la tradición occidental, el liberalismo fue un fermento innovador en Europa de principios del siglo XIX que surgió de la ideología de la Ilustración. El nacionalismo fue un fenómeno significativo a las nuevas ideas y a la Revolución Francesa (el Antiguo Régimen se basaba en el derecho dinástico y la vida de los pueblos dependía de dichas dinastías) ante la mayoría: sentimientos nacionales, costumbres, lenguas y tradiciones.

En resumen, la arquitectura representó el espíritu de una época, una sensibilidad colectiva, una costumbre antropológica, por lo tanto, una cultura humana. La industrialización crea la necesidad de construir edificios como fábricas, estaciones de ferrocarriles, viviendas y demanda, al mismo tiempo, que estos sean baratos y de rápida construcción; sin embargo, aportó soluciones técnicas a las nuevas necesidades, por ello la arquitectura y el urbanismo se vinculan indisolublemente al desarrollo de la industrialización.

Con la Revolución Industrial se inició el cambio climático en la tierra, además se modificó la técnica constructiva; los materiales tradicionales como la piedra, el ladrillo, la madera, estos elementos fueron trabajados de manera racional y distribuidos más libremente; se unen nuevos materiales como la fundición, el vidrio y luego el hormigón. Los progresos de la ciencia permitieron poner en práctica los materiales y medir su resistencia; mejorar las instalaciones de las edificaciones, se difundió el uso de las maquinarias para la construcción, finalmente, el desarrollo de la geometría permitió representar el dibujo de forma rigurosa y unívoca en todos los aspectos de la futura industria de la construcción en la modernidad.

La creación de escuelas especializadas también brindó a la sociedad un gran número de profesionales preparados; al mismo tiempo la imprenta y los nuevos métodos de reproducción gráfica permitieron la difusión de todos los adelantos científicos.

La investigación científica influyó en las técnicas de la construcción, modificando los instrumentos de proyectar, en tanto dos grandes innovaciones como la invención de la geometría descriptiva y la introducción del sistema métrico decimal. La enseñanza de la arquitectura que se impartió durante el régimen antiguo en la Academia Real de la Arquitectura fundada en 1671, contribuyó a la exhibición de la arquitectura francesa, que a lo largo de todo su proceso histórico generó súbitas explicaciones hipotéticas entre la razón y el sentimiento en el arte, en tanto fueron los nuevos signos y paradigmas de una revolución cultural y filosófica entre el arte y la ciencia.

Ahora bien, la ciencia es una herramienta esencial para la sociedad del siglo XXI. Desde el principio de la historia humana, el hombre estuvo interesado en la locomoción, los primeros vestigios del hombre antiguo siempre estuvieron vinculados al tema del agua, no se alejaba de la fuente de vida, apareció el invento de la balsa, sin embargo, el matemático, físico, teólogo y filósofo Blaise Pascal fue un polímata, decía que los ríos son caminos que se mueven, probablemente el tema fluvial contribuyó a los primeros humanos a colonizar América que se extendieron por el mundo.

En la civilización contemporánea actual no podemos dejar de reconocer la rueda como el invento que cambio el curso de la historia para facilitar el transporte de grandes cargas, desde la rudimentaria forma de angarillas hasta la aparición del trineo como paradigma 
de un conjunto de valores que ha permitido las diferentes maneras de ver el mundo como es el caso de las producciones espaciales del arquitecto Le Corbusier quien utilizó las líneas y volúmenes propios del automovilismo y los trasatlánticos con el propósito de mecanizar la arquitectura.

El efecto trasbordador de los principios de Le Corbusier a la enseñanza de la arquitectura, en un momento determinado, tuvo un realismo científico en muchas obras del pasado presente moderno, la inconmensurabilidad de sus analogías sirvieron de axiomas, deducciones y estrategias en el desarrollo de la arquitectura moderna en el mundo y en muchas de las escuelas de enseñanza de la arquitectura e incluso al día de hoy.

\section{B. La enseñanza universitaria y la ciencia de la arquitectura}

La ciencia de la arquitectura respecto a la época de la enseñanza-aprendizaje de una Facultad de Arquitectura en el mundo ha variado mucho en el campo de la pedagogía, el proceso de construir un discurso visual vive en la intangibilidad del espacio conceptual. La necesidad de nuevos espacios de investigaciones, innovaciones y exploraciones académicas es imprescindible para el desarrollo de las nuevas miradas y construcciones de los conocimientos en torno a las transformaciones y desafíos presentes en el campo de la enseñanza de la arquitectura.

El gran Galileo Galilei ${ }^{3}$ decía que nada puedes enseñarle a un hombre, sólo puedes ayudarlo a que lo descubra dentro de sí mismo porque cada ser humano es algo nuevo, como algo que no existía antes, un ser distinto dotado de todo lo necesario para triunfar en la vida por derecho propio; cada uno puede

3 Fue un importante creador, astrónomo, filósofo, ingeniero, matemático y físico italiano, relacionado a la revolución científica. Eminente hombre del Renacimiento, mostró interés por casi todas las ciencias y artes (música, literatura, pintura). Sus logros incluyen la mejora del telescopio, gran variedad de observaciones astronómicas, la primera ley del movimiento y un apoyo determinante a la Revolución de Copérnico. Ha sido considerado como el "padre de la astronomía moderna", el "padre de la física moderna" y el "padre de la ciencia". ser una persona importante, pensante, consciente y productivamente creadora porque la educación, asimismo, se interesa en crear un valor al estudiante a convertirse en un todo organizado y significativo.

En otras palabras, todos los hombres tienden por naturaleza a saber, Aristóteles planteaba el "saber por excelencia" y sostenía que el bien es el fin supremo de todas las acciones del hombre; de todas las ciencias, las artes, y las indagaciones del espíritu, tienen siempre por mira algún bien que deseamos conseguir. El bien supremo es la felicidad, pero es cierto que la felicidad no es lo mismo para todos; unos la colocan en el placer carnal y pasajero, otros, como el pobre de espíritu en la riqueza, el enfermo en la salud, el mendigo en el pan de cada día; el vanidoso y poderoso en el poder y dinero, ignoran que el hombre vale por su saber, niegan que la cultura es la más honda fuente de la virtud más allá del tiempo y del espacio; por eso, no olvidemos que la verdadera felicidad es la obtenida por la práctica de la virtud mediante el largo aprendizaje de la enseñanza universitaria, aún afuera de los muros de la universidad.

En las últimas décadas de vida universitaria se ha dado cabida a muchas carencias y debilidades humanas -ausencia de vida interior-, los defectos que superan a las virtudes siempre son justificados, la falta de ética respecto a la enseñanza-aprendizaje alienta el egoísmo, el orgullo, la competencia -ganar o perder-, aferrarse a un modelo pedagógico, examinar modelos mentales de la realidad, nunca la verdad y alejado del aprendizaje profundo. Necesitamos encontrar el sentido del amor por los conocimientos, la profundidad de los conceptos, aprender a elevar nuestra propia conciencia y saber eliminar la contaminación psicológica, a saber aplicar y trasmitir las enseñanzas, como fueron los ejemplos, experiencias y éticos los maestros y arquitectos Juan Romero Almendras y Félix Mayorca Palomino.

El aprendizaje y la memoria del ser humano son dos acciones totalmente relacionadas, de unir educación y neurociencia como un diálogo de formación horizontal, así pues, el áci- 
do desoxirribonucleico -ADN-, contiene la información de las características hereditarias de cada ser vivo, es una proteína compleja que se encuentra en el núcleo de las células y constituye el principal constituyente del material genético de los estudiantes y docentes de la Facultad de Arquitectura y Urbanismo.

Hay que destacar que Albert Einstein, decía que la creatividad es la inteligencia divirtiéndose, además que la imaginación es más importante que el conocimiento; este estudioso físico alemán de origen judío, fue considerado como el científico más importante del siglo XX. Su madre tocaba el piano y le transmitió a su hijo el amor por la música. El colegio no lo motivaba y, aunque era excelente en matemáticas y física, no se interesaba por las demás asignaturas, por lo que discutía frecuentemente con sus profesores, siendo esta experiencia una relación asimétrica.

En la interacción analítica del proceso educativo respecto a la fórmula estudiante-docente, los vínculos de la personalidad, los conocimientos, las habilidades didácticas y las formas de interacción en el aula; son el resultado activo y han puesto de manifiesto la necesidad de atender los procesos académicos, científicos, tecnológicos, culturales, psicológicos y sociales, asimismo como importante son los factores contextuales que afectan la gestión pedagógica y comprenden los resultados de la formación profesional.

El año 1954 Mathias Goeritz ${ }^{4}$ teorizaba el principio de la "arquitectura emocional", apelaba a la necesidad de idear espacios, obras y objetos que causen al hombre moderno una máxima emoción, frente al funcionalismo industrial y la pose estética forzada de la arquitectura. Construir edificios para emocionar, no para mayor ego del autor o mayor pragma-

4 Alejado de la guerra viajó por Europa y África y llevó a cabo una exposición en España en septiembre de 1949 en la primera semana de arte en Santillana del Mar, por ese entonces en México las tendencias que primaban eran el indigenismo y el positivismo futurista. Goeritz trabajó durante 40 años como arquitecto y artista fusionando la utopía racional con el neoprimitivismo (Cadenas, 2014). tismo de su uso posterior. Su idea era recuperar las funciones sociales del diseño.

Las teorías cognitivas se centran en el estudio de la estructura y desarrollo de los procesos de pensamiento y de qué manera afecta la comprensión de las personas sobre su entorno. Jean Piaget ${ }^{5}$, educador, psicólogo e investigador más importante de la historia decía que:

En un contexto histórico en que se daba por sentado que los niños y niñas no eran más que "proyectos de adultos" o versiones imperfectas de ser humano, Piaget señaló que el modo en el que los pequeños actúan, sienten y perciben, denota no que sus procesos mentales estén sin terminar, sino más bien que se encuentran en un estadío con unas reglas de juegos diferentes, aunque coherentes y cohesionadas entre sí. (Triglia, 2018, párr.4)

Nuestra mente está preparada para pensar sobre el pasado y desde el pasado, Piaget sabía que era absurdo intentar por separado los aspectos biológicos y los aspectos relativos al desarrollo cognitivo. La mente humana no es algo que este separada del cuerpo, en tanto las cualidades físicas dan forma a los procesos mentales, es un proceso de construcción permanente de nuevos significados, lo que sucede con los estudiantes de nuestra casa de estudios.

Carl Jung, distinguido psiquiatra suizo nacido en Kesswil el año 1875, señaló que los procesos psíquicos no sólo debían ser intelectualmente comprensibles, sino emocionalmente sostenibles. La vivencia de vida universitaria es importante porque permite acceder a contenidos de nuestra psique que son desconocidos, así, pues, lo único directamente experimentable del mundo, son los contenidos de la conciencia, la forma cómo se organizan esos contenidos en la universidad porque también, se vinculan a las condiciones del entorno personal de los estudiantes,

\footnotetext{
5 Piaget consideraba que los patrones de pensamiento y comportamiento de los más jóvenes son cualitativamente distintos con respecto a los de los adultos, y que cada etapa de desarrollo define los contornos de estas maneras de actuar y sentir. (Web del maestro, 2018)
} 
docentes y graduados de nuestra comunidad universitaria.

Para Jung, la finalidad de la educación es promover los procesos de crecimiento personal de nuestros estudiantes, el alma es un reflejo del mundo y del hombre, es decir su diversidad cultural proyectada en diferentes puntos de vista, la imagen de la propia alma; porque, cada cual hace su propia imagen del mundo y construye para ese mundo particular, un sistema privado. La realidad del mundo tiene la dimensión de la conciencia, sostenía que posiblemente hay, en el mundo de la realidad objetiva, tanto desconocimiento como contenidos inconscientes hay en la psique de un individuo.

Dicho de otra manera, el inconsciente personal de un estudiante de la Facultad de Arquitectura y Urbanismo constituye la memoria individual y profunda de su personalidad creativa, simultáneamente contiene vivencias y experiencias individuales, los pensamientos (incluso los olvidados), las sensaciones, los deseos y las proyecciones a acciones futuras. Por otro lado, el inconsciente colectivo se construye a partir de los símbolos y conceptos universales, comunes a todos los estudiantes y docentes; en otras palabras, son los instintos, los mitos, la cultura, las religiones, la historia, las experiencias; hay que destacar que Jung llamó "arquetipos" a este conjunto de imágenes y representaciones universales tan propios y culturales en cuanto al modo de plantear los problemas de formación profesional y en cuanto a la manera de resolverlo.

Un punto adicional, son las imágenes del sueño que no esconden un deseo insatisfecho, sino que revelan significados profundos, no están generadas necesariamente por un conflicto interno. Jung tiene un planteamiento más constructivo que Freud, en cuanto cree que el sueño tiene una función compensadora y educativa.

La historia de la arquitectura y la ciencia son el uno y el otro, entre lo finito y lo infinito, siempre se han visto estrechamente relacionadas, esto desde la antigüedad, ya que muchos filósofos, arquitectos y artistas han intentado definir la arquitectura como una ciencia; hay que tener en cuenta el uso, manejo y dominio de muchas disciplinas científicas y técnicas en definitiva. La filosofía de la arquitectura definida por el primer teórico de la lógica arquitectónica es el caso de Marco Lucio Vitruvio Polión, quien aseguró: "La arquitectura es una ciencia adornada de otras muchas disciplinas y conocimientos".

\section{El planificador y visionario Juan Romero} Almendras

El destacado magíster Juan Romero Almendras, fue un docente de muchas promociones estudiantiles, que durante su labor pedagógica en la formación de profesionales de la Facultad de Arquitectura y Urbanismo de nuestra casa de estudios, contribuyó a forjar destacados arquitectos esparcidos a nivel nacional e internacional, siempre estuvo a la altura de los cambios educativos a favor de la universidad, desperdigó sus actos académicos con un nivel de nobleza humana, digno de un maestro, cada una de sus clases era un aprendizaje vivo, pensante y objetivo, un innovador nato que propugnaba el ejercicio de la construcción -en época de estudiantes- como medida útil de las técnicas y métodos de los trabajos de campo y análisis profesional. No obstante, apostaba por la investigación científica, era un convencido por el método experimental y las nuevas teorías sujetas a cambios de las culturas y códigos de comunicación.

Cuando hoy en día enfocamos nuestra atención en Juan Romero Almendras se debe a las muchas reflexiones que tuvimos cuando fuimos estudiantes sobre el desarrollo de la Universidad como preludio respecto al porvenir de la enseñanza superior. Me contaba que su maestro había sido el arquitecto Luis Miró Quesada Garland, quién lo introdujo en la docencia y en la especialidad, siempre tuvo frases honorables y felices, un recuerdo eterno y la magia de la nobleza que acompañan el brillo personal y destaque académico, virtudes de todo maestro en estos tiempos convulsionados. Creía en los cambios pedagógicos, en el valor de la verdad, era un intelectualista que despertaba la conciencia de los estudiantes, entendía que los conocimientos no sólo 
tienden a envejecer, sino a transformarse en verdadera rémoras y encendía pasión moderada en sus observaciones, críticas y respuestas, siempre atento y preocupado por los estudiantes y vigilante sobre la marcha académica y administrativa de nuestra Facultad en aquellos años. En su texto Forma y Diseño, urbanismo y arquitectura, señaló que:

Nunca como ahora han sido tan necesarios la creatividad y el sentido crítico de los profesionales del hábitat. El explosivo crecimiento demográfico, la creciente dificultad en la disponibilidad de recursos, los desequilibrios en el aprovechamiento de los beneficios de la urbanización, el uso irracional y caótico del suelo urbano; todo esto frente a los nuevos problemas habitacionales que surgen en el seno de una sociedad que replantea sus modos de existencia, hace más imperativo el surgimiento de profesionales capaces de conocer, comprender e interpretar los nuevos problemas y desarrollar soluciones acordes con las aspiraciones de la sociedad. (Romero, 1985, p.7)

Así mismo, Romero señala que:

Tampoco nunca como hoy, la formación de los futuros profesionales del hábitat en los talleres universitarios, ha sido tan poca rigurosa y escasamente sustentada en planteamientos teóricos y metodológicos coherentes con las exigencias de la sociedad. La inusitada masificación de las aulas y talleres, coincidente desde hace más de quince años con la aplicación de políticas de desactivación sistemática de la institución universitaria, no significó una reacción de los planteamientos formativos, ni en la reorientación de los planteamientos teóricos y metodológicos acordes con la nueva situación, ni significó una reacción vitalizadora en defensa de la presencia de la Universidad en la vida nacional. (Romero, 1985, p.7).

Entre sus ideas pedagógicas, se percibía que el problema de estructurar una metodología que permita relacionar la forma urbano-arquitectónica con el diseño, es decir, con el proceso de producirla, consideraba que era significativa para ordenar los aspectos del di- seño en relación a los factores que se conjuga con la naturaleza de la forma, con el propósito de hacer coherente el proceso de diseñar y configurar una forma habitacional, decía que la metodología debía orientar el diseño urbano-arquitectónico y el ejercicio de la crítica y autocrítica frente al conocimiento de los problemas habitacionales y el proceso de autoformación. Un aspecto singular de la docencia de este querido profesor fue su vida académica con los estudiantes -en la calle Piura cuadra cuatro en el distrito de Miraflores-, en un contexto diverso y un ambiente de aprendizaje sano, atractivo y seguro, siempre a fortalecer su vocación de servicio. Se interesaba mucho por los problemas de aprendizaje de sus estudiantes, era amante de la buena conversación, gozaba con los aportes de sus aprendices, fomentaba la críticaautocrítica y se preocupaba por los asuntos fundamentales de la universidad, sostenía la vigencia de la tecnología y sus adelantos de visualización cerebral, era metodólogo y científico por la excelencia en la educación -hoy en día se pregona la neurociencia-, fue un adelantado a su época, a favor de la educación socio-emocional y la creatividad para

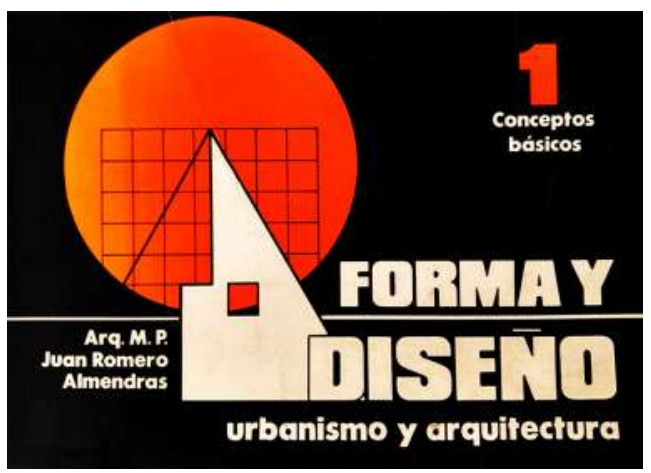

Figura 1. Carátula del texto del planificador y arquitecto Juan Romero Almendras, se elaboró su primera edición en el año 1985. Fue patrocinado en sus inicios por Aporte promoción a la cultura, un proyecto universitario, que surgió en el interior de las aulas con la presencia de los estudiantes en aquella época, hoy profesionales Andrés Pomposini, Enrique Bonilla y Walter León, graduados por la Universidad Ricardo Palma. Fue una aventura académica, producto de la interacción del taller de diseño a cargo de Juan Romero Almendras como ejemplo de la autonomía universitaria, en aquellos años (Fotografía: León, 2017). 
resolver los problemas de la vida, actividades para trabajar como el optimismo, el autocontrol y la resiliencia, fomentaba el clima emocional positivo en el aula y auspiciaba una cultura pedagógica innovadora.

Fue un visionario ${ }^{6}$ de la pedagogía universitaria, respecto a los procesos formativos de los talleres de enseñanza de la arquitectura en la que los estudiantes podíamos ejercer el autocontrol de nuestras producciones y la formación profesional, en ese sentido, la producción de formas se fundamentaba en teorías, es decir, en un sistema de ideas que procurábamos explicar e interpretar a la coherencia entre la práctica de producir formas urbano-arquitectónicas y los problemas habitacionales.

Destacaba por medio de sus enseñanzas dentro y fuera del aula, en primer lugar, la necesidad de aprender a aprender, es decir a comprender el mundo que lo rodea, el placer por la curiosidad y la adquisición científica del conocimiento, simultáneamente a conocer la naturaleza y el afán por descubrir formas físicas habitables por el hombre; en segundo lugar, aprender a hacer, mediante la racionalidad y objetividad, aplicar conceptos, juicios y raciocinios, "enseñaba a pensar", prestaba atención a que los estudiantes ejercieran la teoría como la práctica, es decir un semestre se dedicaba el alumno a diseñar el objeto de estudio y el siguiente ciclo dirigía y ejecutaba el proceso y la obra producida por los estudiantes del Taller N.․ 14 -en aquella época- experimentaban la verificación de sus diseños; en tercer lugar, aprender a convivir; predicaba la competencia emocional

6 El educador, arquitecto y magíster Juan Romero Almendras, fue un teórico y científico probo y gestor de la unidad urbano-arquitectónico-medioambiental, señalaba que el hábitat es el resultado del modo como la sociedad organiza, modifica, transforma el medio natural para adaptarlo a sus necesidades de habitación, útil para desarrollar sus modos de organización económica, política, etc.; sus modos de entender y usufructuar la naturaleza; sus modos de concentración o dispersión en el territorio. Un aspecto significativo y aporte de este educador sostenía que la forma urbano-arquitectónica es la estructura cultural del hábitat desde la cual, la sociedad ejerce dominio sobre el contexto regional y nacional a través de las decisiones de producción, intercambio, etc. mediante la empatía y las habilidades sociales, el buen servicio profesional basado en el autocontrol, los impulsos y las emociones para tener éxito en el trabajo para persuadir o inspirar a los demás y poder dirigir equipos, un postulado fundamental en la comprensión del urbanismo, participar y colaborar con los demás.

Nos enseñó a aprender a creer y aprender a ser, creía en la capacidad del estudiante, en una ocasión pedagógica y didáctica de un viaje de estudios a la localidad de Callahuanca, provincia de Huarochirí, cuyo nombre proviene del quechua cajlla y huanca que en español quiere decir "Piedra Grande". Tuvimos la oportunidad de formular y diseñar un nuevo hábitat para sus habitantes, la experiencia fue extraordinaria por sus resultados; casi una semana de levantamientos urbanos, diagnósticos arquitectónicos, interacción con las autoridades del lugar, luego en el taller de diseño con las exposiciones de propuestas y, lo más importante, un aprendizaje significativo que al día de hoy, muchos graduados recuerdan la bondadosa docencia.

\section{El pragmático y educador Félix Mayorca} Palomino

Si contemplamos pedagógicamente el Taller Integral de Diseño № 8, de la Facultad de Arquitectura y Urbanismo de la Universidad Ricardo Palma, cuya filosofía educativa se sustenta en el concepto de Comunidad de Aprendizaje Mutuo (CAM), surgió en el año 1999 como alternativa del rol de la tecnología en la enseñanza-aprendizaje de la arquitectura y como proyecto de transformación de innovación tecnológica. Una reseña histórica respecto a la fundación, gestión y desarrollo del Taller Virtual en su primera parte dirigida por el recordado arquitecto Félix Mayorca Palomino, es posible conocer a detalle 


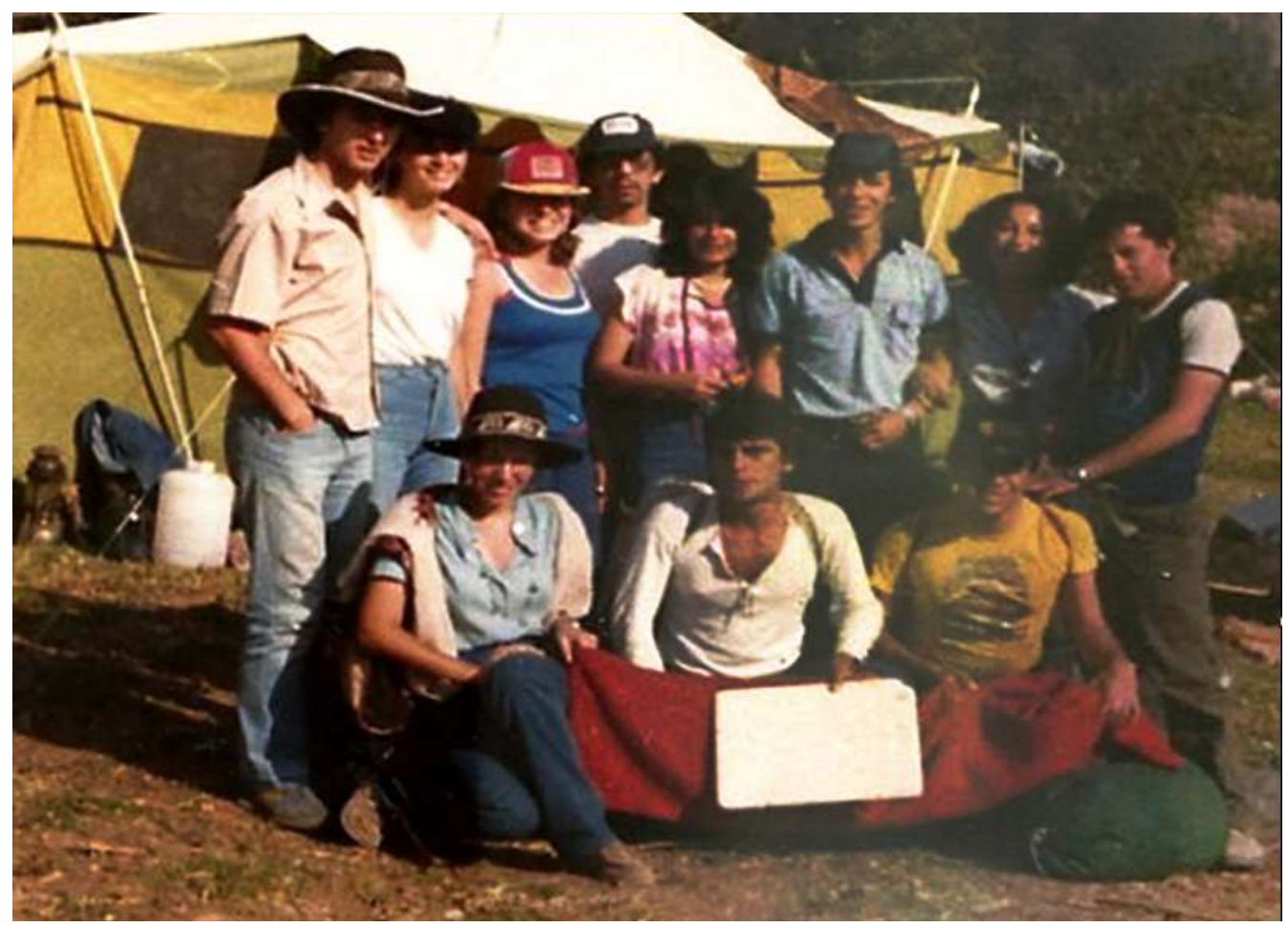

Figura 2. Un grupo de estudiantes de la Facultad de Arquitectura y Urbanismo, en la visita a la localidad de Callahuanca, por motivo de estudios académicos. Entre ellos, Eduardo Dreifuss, Violeta Málaga, Roxana Albornoz, Walter León, Malena De La Torre, Sergio Arata, Jenny Zúñiga, Alex Ángeles, abajo Gladys Perez-Egaña, Josué Gómez. Experiencia académica maravillosa y recuerdos inolvidables (Fotografía: León, 1979).

gracias al talentoso bachiller Gonzalo Chong Pascual ${ }^{7}$.Nuestros egresados coinciden que el compromiso de aportar nuevas metodologías de trabajo y producción basadas en el aprovechamiento de las ventajas competitivas generadas por la creciente penetración de los sistemas informáticos, es una realidad.

Vamos a reflexionar sobre la constelación del dedicado educador universitario Félix Mayorca Palomino -in memoriam-.antes de partir a mejor vida, tuvo una gran satisfacción cuando un grupo de estudiantes del Taller

7 En la página 58 de la revista pedagogía y arquitectura, P\&A, del Departamento Académico de Arquitectura de la Facultad de Arquitectura y Urbanismo de la Universidad Ricardo Palma, año 2, enero-julio de 2017, en su artículo "La emergencia del taller virtual como colaboratorio de la innovación arquitectónica", realiza un análisis técnico, funcional y ético sobre los aportes y ventajas de la enseñanza por competencias. Es un enfoque muy relevante del taller virtual.
Integral de Diseño Arquitectónico N.` 8 ganó el "II Concurso Nacional de Arquitectura en Fierro y Acero 2009", el 24 de setiembre del mismo año, en el que participaron universidades como la Pontificia Universidad Católica del Perú, la Universidad Peruana de Ciencias Aplicadas, la Universidad Nacional de Ingeniería; con el patrocinio del Instituto Latinoamericano de Fierro y Acero (ILAFA) y con el auspicio de la empresa Aceros Arequipa.

La distinción otorgada por el jurado estuvo compuesto por los arquitectos Rodrigo Mazuré, Emilio Soyer y Adolfo Córdova. El equipo ganador estuvo conformado por los estudiantes: Paolo Díaz, Enrique Cueva y Willy Maita bajo la dirección de los arquitectos Walter León Távara y Félix Mayorca Palomino, en aquella época, jefe del Taller de Diseño Integral N. 8 de la Facultad de Arquitectura y Urbanismo. 


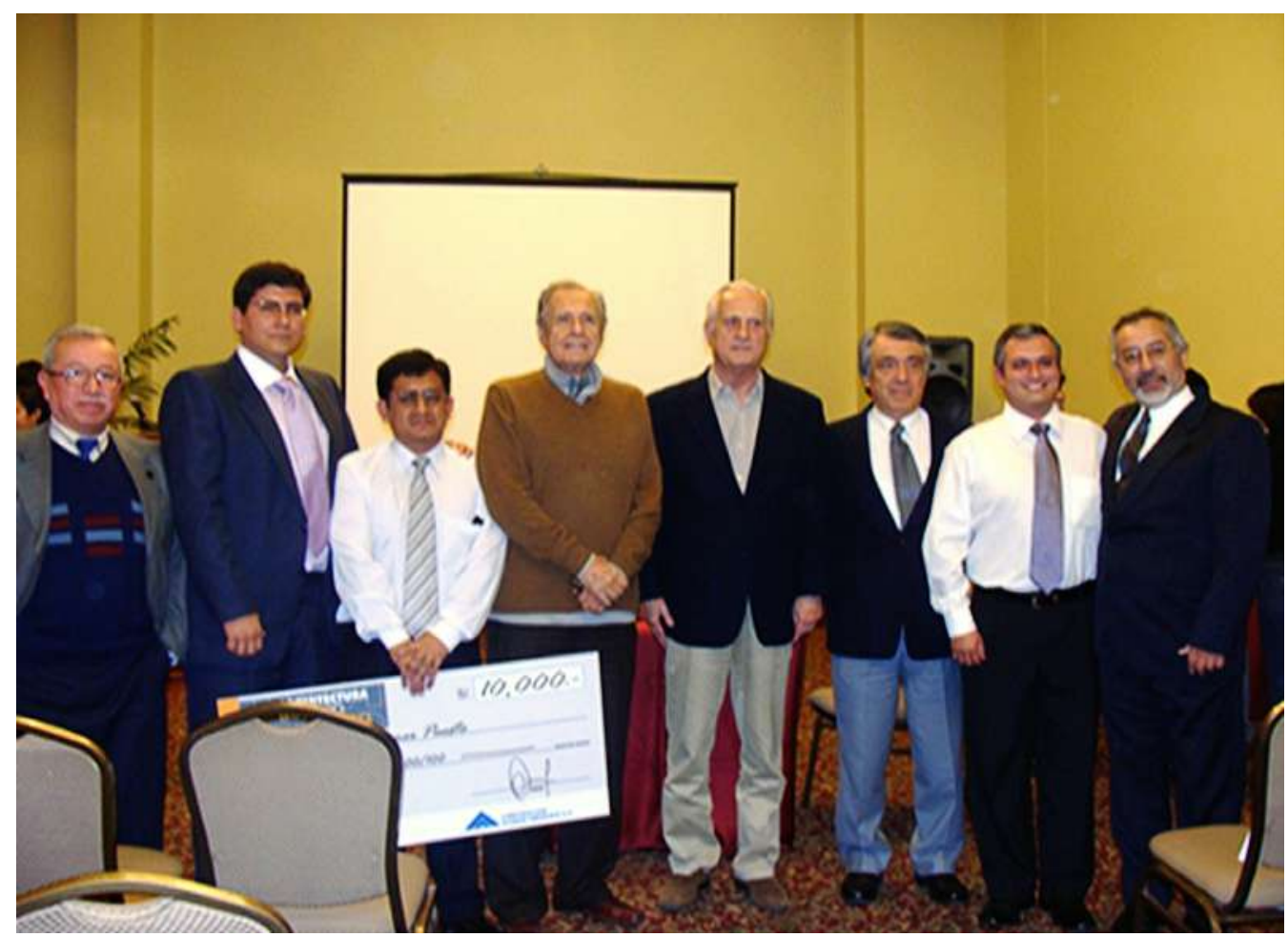

Figura 3. Los estudiantes ganadores, del "II Concurso Nacional de Arquitectura en Fierro y Acero 2009", celebrado el 24 de setiembre del mismo año, organizado por la empresa Aceros Arequipa. De izquierda a derecha: Arquitecto Félix Mayorca, estudiantes Paolo Díaz y Willy Mayta, arquitectos Rodrigo Mazuré, Emilio Soyer y Oswaldo Velásquez, estudiante Enrique Cueva y arquitecto Walter León (Fotografia: Pinillos, 2009).

Hay que destacar que el famoso James Clerk Maxwell (1831-1879) fue un físico británico conocido principalmente por haber desarrollado la teoría electromagnética clásica, sintetizando todas las anteriores observaciones, experimentos y leyes sobre electricidad, magnetismo y aun sobre óptica, en una teoría consistente. Las ecuaciones de Maxwell demostraron que la electricidad, el magnetismo y hasta la luz, son manifestaciones del mismo fenómeno: el campo electromagnético. Por eso, James Clerk Maxwell, estuvo en la Facultad de Arquitectura y Urbanismo, de nuestra casa de estudios a través de la propuesta del Taller Integral de Diseño Arquitectónico N. 8.

Con la propuesta Gravedad Cero, basada en la conceptualización de un módulo magnético de doble polaridad, denominado arquitectura en acero para un Terminal Aeroportuario, se logró que el sistema de doble anillos y de polaridad opuesta interactuando al mismo tiempo, tratando de atraerse y detraerse, creando un campo de doble polaridad en un mismo espacio y en consecuencia la levitación del nodo gravitatorio.

En la inauguración del primer día de clases y presentación de los docentes en el semestre 2015-I, el director de Taller 8 en ese momento -hoy es dirigido por el doctor Simone Censi- el arquitecto Félix Mayorca Palomino, decía:

...en un mundo que cambia con tal velocidad el sistema de pensamiento tradicional de enseñar la arquitectura en las escuelas está fracasando porque no se diseñó una nueva alternativa para hacer frente al cambio. El sistema actual de la enseñanza 


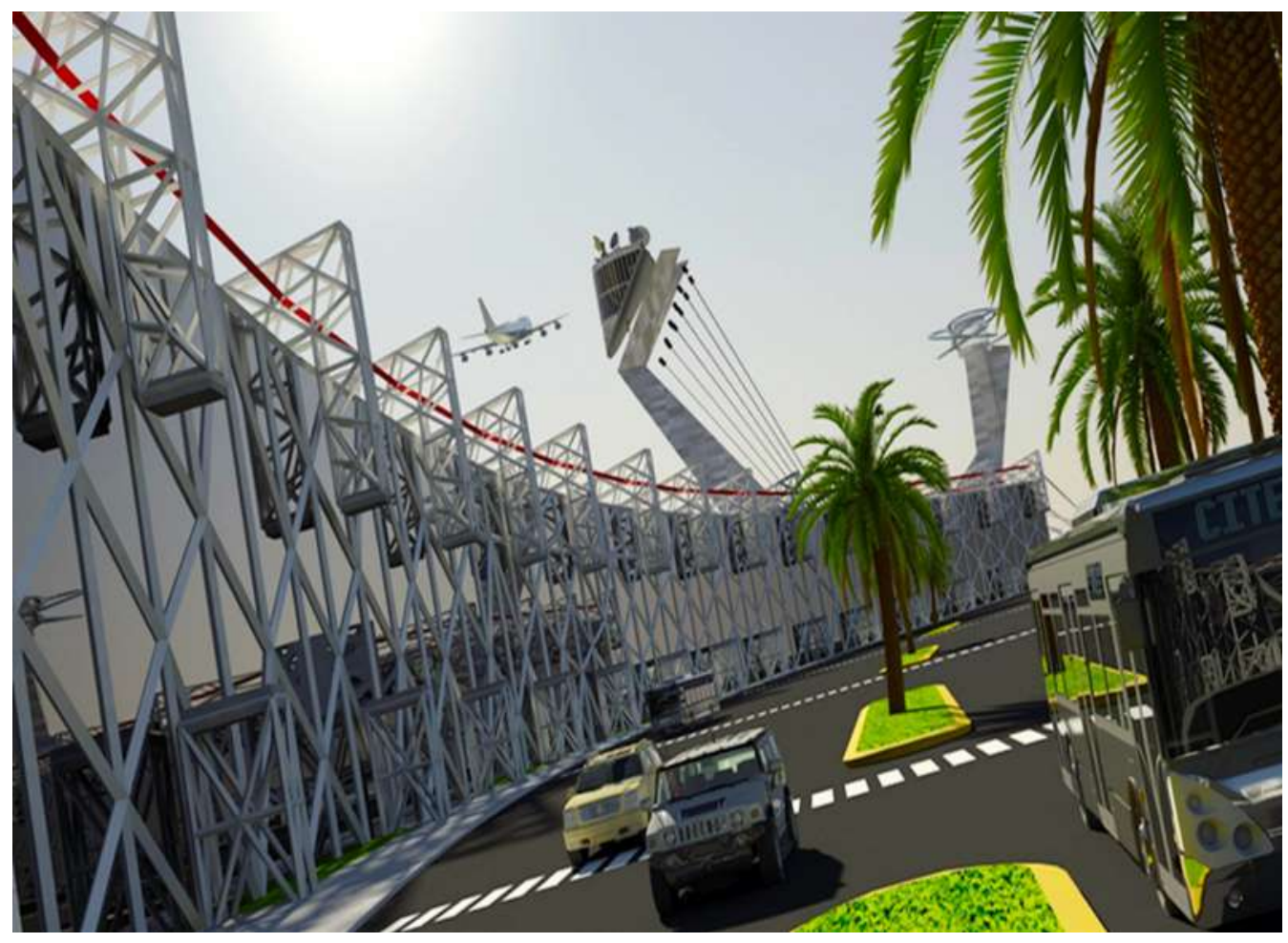

Figura 4. Render elaborado por el equipo ganador, quienes propusieron un sistema de dobles anillos y de polaridad opuesta. Este es el principio base de toda la concepción del proyecto, de esta manera interactuando las fuerzas de los magnetos, tratará de atraerse y a la vez retraerse; de este modo, se crea un campo de doble polaridad en un mismo espacio y por ende la levitación del nodo gravitatorio (Fotografia: León, 2009).

es peligroso e innocuo, por ello Mayorca apostaba por la innovación.

En otras palabras, Félix Mayorca Palomino decía que el futuro siempre trae sorpresas y lo que fue correcto en el pasado no tiene por qué ser correcto en el futuro, por eso son necesarias las experiencias innovadoras, como Picón (2002, p.21) señaló:

Las innovaciones apuntan a las transformaciones. Ellas implican modificar prácticas rutinarias y estilos pedagógicos erosionados en su capacidad de convocatoria educativa. La voluntad de cambio es la primera condición del éxito para una innovación significativa. Saber por qué cambiar, aprender a lograr consensos con las fuerzas refractarias, lograr el apoyo de los sujetos educativos, pero sobre todo desarrollar un estilo de liderazgo participativo, es una de las condiciones básicas para lograr iniciar las innovaciones en el sistema educativo.

Desde luego, para Félix Mayorca Palomino los valores institucionales eran muy importantes como la puntualidad, la responsabilidad, la transparencia, la innovación, el trabajo en equipo y compromiso social, por ello defendió el Taller Integral de Diseño N. 8 comúnmente conocida como "Taller virtual" o "Súper 8"- porque propició el desarrollo educativo en los estudiantes y docentes estimulando el pensamiento crítico y estratégico hacia un comportamiento ecológico comprometido con la sociedad mediante el fomento de políticas pedagógicas acorde con la sostenibilidad, la innovación y el proceso de diseño en contra de los problemas medioambientales que continúan amenazando la continuidad de la vida. 


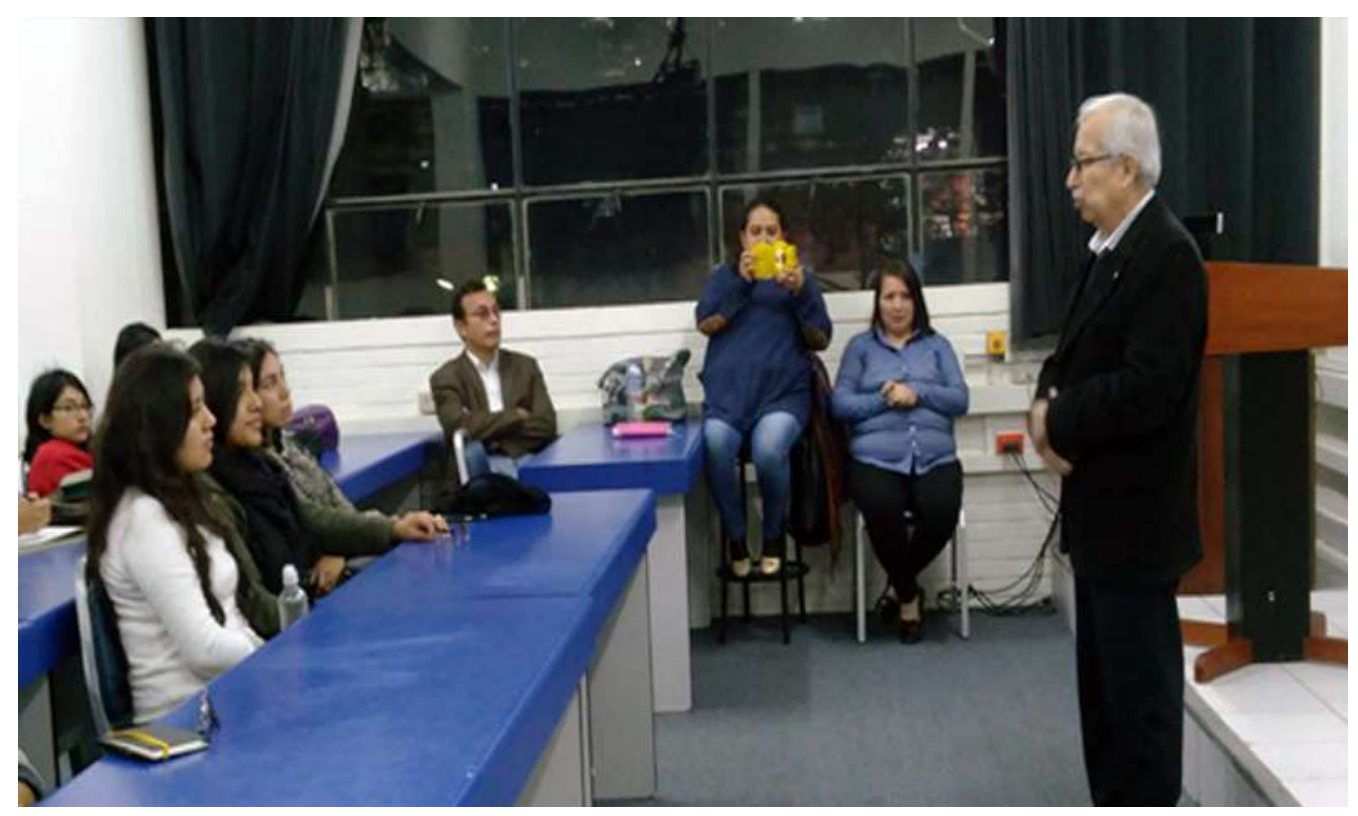

Figura 5. El arquitecto Félix Mayorca Palomino y fundador del primer taller de enseñanza en medios digitales en el Perú, en una charla ante los estudiantes del Taller de Diseño Integral N. ${ }^{\circ}$, de la Facultad de Arquitectura y Urbanismo de la Universidad Ricardo Palma. En segundo plano se observan al doctor arquitecto Pedro Hurtado Valdez, y las arquitectas Ruth Suica Delgado y Amelia Fuentes Rocha, docentes actuales del taller de diseño (Fotografía: León, 2015).

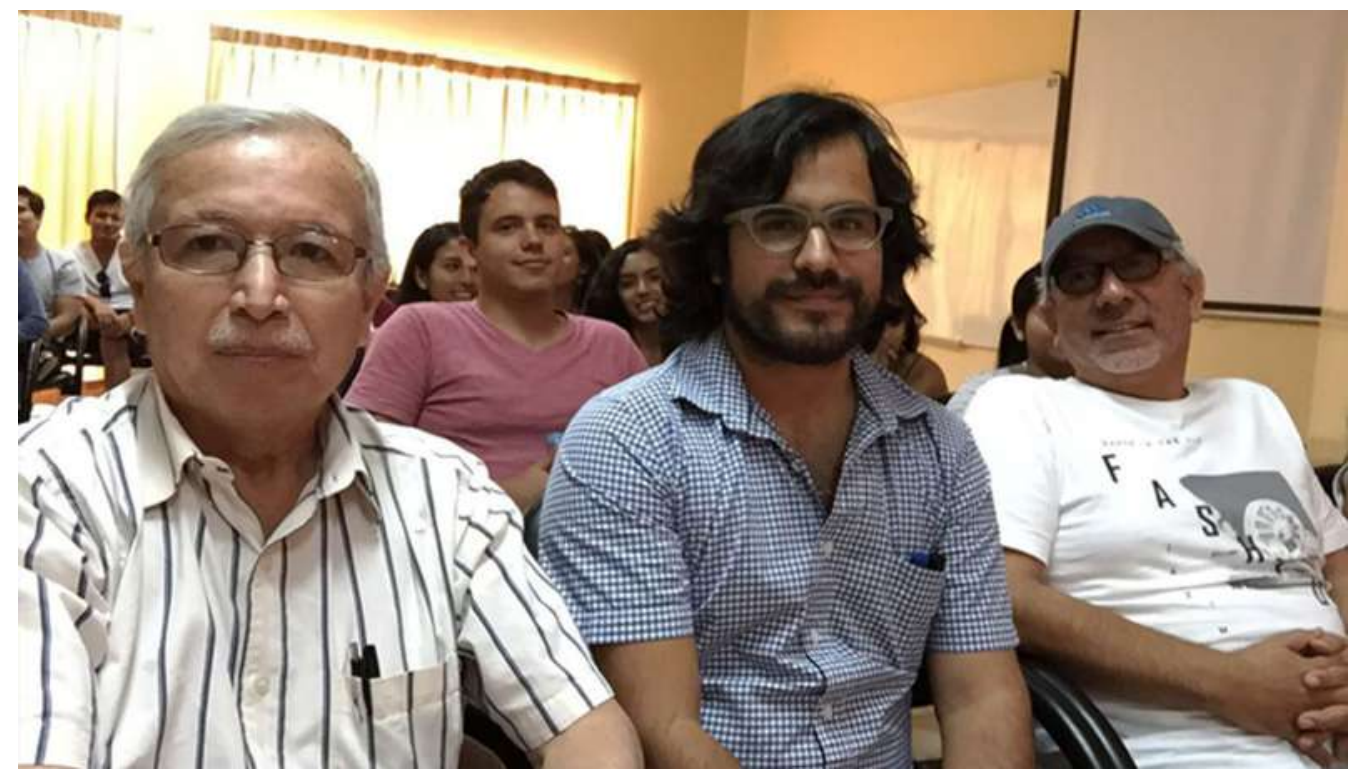

Figura 6. Con la presencia de los arquitectos Félix Mayorca Palomino; José Francisco Lazarte Castillo, representante del Gobierno Regional de Ica y graduado de nuestra Facultad de Arquitectura y Urbanismo; y el magíster Walter León Távara, docente del Taller N. ${ }^{\circ}$; en segunda línea, el estudiante Leonel Sánchez, durante la exposición de los representantes del Gobierno Regional de Ica (Fotografía: León, 2016). 
El manifiesto pedagógico de la Comunidad de Aprendizaje Mutuo (CAM), permitió alcanzar metas académicas, científicas, sociales, culturales y tecnológicas; cooperando y colaborando, "unos con otros", aprovechando las propias experiencias estudiantiles, los conocimientos docentes, la ecología emocional para poder maximizar los aprendizajes, al mismo tiempo como metodologías para desarrollar las habilidades socio-afectivas y cognitivas, precisamente para favorecer la interdependencia afectiva y el inconsciente colectivo del taller. Así, pues, está conformado fundamentalmente por arquetipos físicoespaciales, que son formas preexistentes y universales de la conceptualización del proyecto (ideas, garabatos, imágenes, símbolos) que dan forma a los contenidos psíquicos y morfológicos de los contenidos educativos.

Tuvo mucho interés, Félix Mayorca Palomino, en el discurso comprometido que Steve $\mathrm{Jobs}^{8}$-identificado como uno de los más grandes iconos del mundo empresarial y educativo de todos los tiempos- pronunció en la Universidad de Stanford en el año 2005.

Fue el fundador de la empresa Apple, dio a conocer el Mac, el iPod, el iPhone, el iPad;

8 Steve Jobs tuvo una vida agitada, en tanto dejó a las y los jóvenes lecciones de vida, como un modelo de coraje, de iniciativa y de creatividad. En el texto Steve Jobs (Blumenthal, 2012) libro inspirador para los jóvenes que no están dispuestos a renu nciar a sus sueños, se le a denominado autodidacta, visionario, intuitivo, iconoclasta, diferente e inventor.

\section{Referencias}

Cadenas, L. (2014). Mathias Goeritz: arquitectura emocional. Recuperado de https://elcorso.es/ mathias-goeritz-arquitectura-emocional/

Kahler, E. (2013). Historia universal del hombre. México D.F: Fondo de Cultura Económica.

Miró Quesada G., L. (1945). Espacio en el tiempo: la arquitectura moderna como fenómeno cultural. Lima: Compañía de Impresiones y Publicidad.

Romero Almendras, J. (1985). Forma y Diseño, urbanismo y arquitectura. Lima: Asociacion Gráfica.

Triglia, A. (2018). Las 4 etapas del desarrollo cognitivo de Jean Piaget. Recuperado de https:// psicologiaymente.com/desarrollo/etapasdesarrollo-cognitivo-jean-piaget productos revolucionarios en el campo del diseño de los objetos, sin embargo, expresó tres historias en su vida, la primera trató sobre como "conectar los puntos"; no puedes conectar puntos mirando hacia delante, solo hacia atrás, hay que tener confianza en el destino, el instinto, el karma; la segunda historia, fue sobre el "amor y la pérdida", al cumplir los 30 años y un año después del lanzamiento del Macintosh, Jobs fue despedido de su propia empresa y la tercera historia, trataba "sobre la muerte", decía no aceptar que el ruido de las opiniones de los demás ahogue la propia voz interior de uno mismo, además, debemos tener el coraje de seguir la intuición de nuestro corazón.

Finalmente, el arquitecto y educador Félix Mayorca, en innumerables oportunidades, pensaba que el futuro de la tecnología iba a cambiar el mundo y también la enseñanza de la arquitectura, sostenía que el desafío era adaptarse y prosperar, tan espiritual como una gran ola, sino te sumerges, no saldrás a frote.

Reservo mi gratitud personal y de todos aquellos -hoy profesionales- en su momento fueron estudiantes agradecidos por las enseñanzas de estos dos exmaestros como fueron Juan Romero Almendras y Félix Mayorca Palomino, que en vida, supieron engrandecer con honestidad, ética y autenticidad, el desarrollo de nuestra querida Facultad de Arquitectura y Urbanismo, hoy en recuerdo de ellos.

Picón, C. (2002). Cambio educativo Itinerario de un educador peruano. Lima: Derrama magisterial.

Victorio, E. P. (2017). Luis Miró Quesada Garland y el discurso de la modernidad en el arte peruano. (1945-1951) Pacarina del Sur. Revista Cultural de Pensamiento Crítico Latino Americano (31). Recuperado de http://pacarinadelsur.com/home/ pielago-de-imagenes/1477-luis-miro-quesadagarland-y-el-discurso-de-la-modernidad-en-elarte-peruano-1945-1951

Web del maestro (2018). Piaget y las cuatro etapas del desarrollo cognitivo. recuperado de https:// webdelmaestrocmf.com/portal/piaget-y-lascuatro-etapas-del-desarrollo-cognitivo/?utm_ source=blogsterapp\&utm_medium $=$ facebook $\&$ fbclid=IwAR2C6pl3iJ9zIoxhDeAGompWXrsc VE_KhxGjJWqobCQgBZjcmvMnPfPIc. 